Article

\title{
The Effects of Great Plains Irrigation on the Surface Energy Balance, Regional Circulation, and Precipitation
}

\author{
David B. Huber, David B. Mechem * and Nathaniel A. Brunsell
}

Atmospheric Science Program, Department of Geography, University of Kansas, 1475 Jayhawk Blvd., 213 Lindley, Lawrence, KS 66045, USA; E-Mails: davidbhuber@gmail.com (D.B.H); brunsell@ku.edu (N.A.B)

* Author to whom correspondence should be addressed; E-Mail: dmechem@ku.edu;

Tel.: +1-785-864-5707.

Received: 10 February 2014; in revised form: 15 April 2014 / Accepted: 16 April 2014 /

Published: 5 May 2014

\begin{abstract}
Irrigation provides a needed source of water in regions of low precipitation. Adding water to a region that would otherwise see little natural precipitation alters the partitioning of surface energy fluxes, the evolution of the planetary boundary layer, and the atmospheric transport of water vapor. The effects of irrigation are investigated in this paper through the employment of the Advanced Research (ARW) Weather Research and Forecasting Model (WRF) using a pair of simulations representing the extremes of an irrigated and non-irrigated U.S. Great Plains region. In common with previous studies, irrigation in the Great Plains alters the radiation budget by increasing latent heat flux and cooling the surface temperatures. These effects increase the net radiation at the surface, channeling that energy into additional latent heat flux, which increases convective available potential energy and provides downstream convective systems with additional energy and moisture. Most noteworthy in this study is the substantial influence of irrigation on the structure of the Great Plains Low-level Jet (GPLLJ). The simulation employing irrigation is characterized by a positive $850-\mathrm{mb}$ geopotential height anomaly, a result interpreted by quasi-geostrophic theory to be a response to low-level irrigation-induced cooling. The modulation of the regional-scale height pattern associated with the GPLLJ results in weaker flow southeast of the $850-\mathrm{mb}$ anomaly and stronger flow to the northwest. Increased latent heat flux in the irrigated simulation is greater than the decrease in regional transport, resulting in a net increase in atmospheric moisture and a nearly 50\% increase in July precipitation downstream of irrigated regions without any change to the number of precipitation events.
\end{abstract}


Keywords: irrigation; regional climate; mesoscale model; WRF; precipitation; low-level jet; LLJ

\section{Introduction}

The impacts of land cover change make it a first-order climate forcing at local and regional scales $[1,2]$. Irrigating croplands in regions where precipitation falls well below the water requirements of the crops has the potential to drastically alter the water and energy balances of those areas [2]. The cooling due to increased latent heat flux has been hypothesized to be an explanation for the discrepancy between global circulation models and observations over the heavily irrigated region of the central United States [3]. Because variability in soil moisture is understood to have a direct impact on altering local and regional precipitation behavior [4-8], irrigation has long been suspected as a source for enhanced precipitation downstream of irrigated regions $[9,10]$.

The primary impact of irrigation is due to changes in the local radiation budget via providing more surface moisture for latent heat $(L E)$. The local cooling due to the increased $L E$ results in a decreased sensible heat flux $(H)$. For example, Adegoke et al. [11] investigated the impact of irrigation using the Regional Atmospheric Modeling System (RAMS) and showed a 36\% increase in latent heat and a $15 \%$ decrease in sensible heat flux between irrigated and non-irrigated simulation in Nebraska. The increase in $L E$ accompanying irrigation leads directly to a decrease in surface temperatures, a result that has been established observationally [12]. The reduced temperature decreases longwave emission from the surface and increases the net radiation $\left(R_{n}\right)$ [13]. The alteration of the surface turbulent fluxes destabilizes the boundary layer over and downwind of the irrigated region by increasing near-surface moist static energy (MSE). The decrease in sensible heat flux leads to a reduction in the rate of boundary layer growth and entrainment of dry free-tropospheric air, which prevents the high-MSE boundary layer air from becoming diluted [14-16].

The enhanced evaporation from an increase in soil moisture has been shown to moisten the boundary layer and influence precipitation processes [7,17,18]. Findell and Eltahir [17,18] found that over areas of relatively high boundary layer moisture with slightly unstable middle-atmospheric profiles (associated with a relatively weak capping inversion), convection is more likely to occur for wet soils. Moreover, for conditions of relatively low boundary-layer moisture and moderately unstable atmospheric profiles, convection is more likely to occur under dry soil conditions. Not surprisingly, they also found that conditions of substantial low-level moisture and/or a very unstable upper atmosphere always promoted convection and were thus rather insensitive to soil moisture. Applying this framework to the U.S. Great Plains showed that convective precipitation in the region occurred under both wet and dry soil conditions, a result attributed to the highly variable atmospheric and soil moisture conditions over the Great Plains. Jones and Brunsell $[6,7]$ showed that both the timescale and magnitude of simulated precipitation events were directly tied to the soil moisture initial condition. Their results indicated a primary impact due to alteration of the energy balance partitioning between latent and sensible heat fluxes, rather than a direct effect via changes to net radiation. 
A number of studies have investigated the effects of irrigation on precipitation. Focusing on irrigation in the Texas panhandle during years with abnormally high precipitation during June or July, Barnston and Schickedanz [9] found a statistically significant relationship between surface warm fronts, stationary fronts, and low-pressure centers and precipitation downstream of irrigated regions. Moore and Rojstaczer [19] investigated anomalously high precipitation in individual precipitation events via radar imagery and rain gauge data, and found a contribution from irrigation of between 6 and 18\% of rainfall downstream, with a maximum effect about $90 \mathrm{~km}$ downwind of the irrigation. They also noted that approximately $10 \%$ of the water evaporated by irrigation was locally recycled. Recent comprehensive modeling studies confirm that irrigation is accompanied by substantial increases in evapotranspiration and smaller increases in precipitation [20,21].

Irrigation has the capability to enhance horizontal gradients in soil moisture and strengthen mesoscale circulations [22]. Garcia-Carreras et al. [23] observed such circulations between the edges of a vegetated cropland region and the surrounding fields of shrub and grass. These circulations were generally located within the boundary layer and were a product of differential sensible heating and subsequent warming within the boundary layer. The circulations resulted in a field of cumulus congestus clouds associated with low-level convergence and uplift. Lohar and Pal [24] investigated the effects of irrigation on convection in Bengal, India, and found that the decreased temperature gradient between land and sea caused by enhanced evaporative cooling from irrigation weakened the land-sea breeze and reduced pre-monsoon convective precipitation. At the same time, a circulation very similar to a land-sea breeze, except located between the non-irrigated and irrigated areas, was observed in their model results. De Ridder and Gallée [25] examined irrigated lands in Israel and found that irrigation substantially destabilized the atmosphere and increased the number of precipitation events. Kueppers et al. [26] found a similar result in the California central valley, where outflow from irrigated regions resulted in boundary layer convection near the boundaries of the irrigated area.

In addition to circulations driven by contrasts between irrigated and non-irrigated regions, many of these studies suggest that irrigation may also affect transport of water vapor at the regional scale. For example, over the central United States, the Great Plains Low-Level Jet (GPLLJ) transports northward additional water vapor arising from irrigated croplands. The rain-fed agricultural areas of the central U.S. are heavily dependent upon moisture advection from the GPLLJ. Enhanced evaporation from irrigation increases boundary layer humidity, which can be advected downstream by the GPLLJ.

Based on results from a modeling study of the flood of 1993, Paegle et al. [27] argued that enhanced evaporation over the Great Plains during the summer months weakened the GPLLJ. However, the net effect of enhanced evaporation and a weaker GPLLJ on moisture transport is not well understood. Global climate model projections suggest the GPLJJ is likely to intensify over the 21st century [28]. Understanding how irrigation interacts with the GPLLJ will be vitally important for fully assessing the ramifications of climate change on agricultural production throughout the region. In this study, we employ a numerical modeling approach to evaluate the impacts of irrigation on the radiation budget, the GPLLJ, and downwind precipitation. In contrast to previous irrigation studies, we particularly emphasize the influence of irrigation on the structure and strength of the GPLLJ and regional moisture transport. 


\section{Methodology}

To ascertain the effects of irrigation on the flow, radiation budget, and precipitation over the Great Plains and Midwest, two simulations (hereafter CTL and IRR) were performed using the Advanced Research (ARW) implementation of the Weather Research and Forecast Model (WRF) Version 3.1.1. WRF is a three-dimensional, non-hydrostatic, fully compressible numerical model [29]. Simulations employed a horizontal grid spacing of $12 \mathrm{~km}$ over a domain that spanned most of the United States (Figure 1). In order to better represent boundary layer processes, we employed a stretched vertical grid, with the grid spacing ranging from $\sim 8 \mathrm{~m}$ at the surface to $\sim 700 \mathrm{~m}$ at $500 \mathrm{mb}$. The simulation timestep was $30 \mathrm{~s}$. The simulations used the Kain-Fritsch convective parameterization [30] and the Yonsei University planetary boundary layer scheme [31]. Although the formulation of the Yonsei University parameterization is simpler than higher-order parameterizations employing turbulent kinetic energy, and the Kain-Fritsch parameterization has known drawbacks in representing organized convection [32], this choice of parameterizations has been extensively evaluated and is suitable for regional climate simulations [33]. The first month of each simulation constituted the spin-up time. The length of the spin-up time was chosen to roughly correspond to the feedback timescale between soil moisture and precipitation [7].

Figure 1. Land cover classification employed for all model cases, plotted over the entire WRF model domain. Regions labeled 1 and 2 are analysis domains that represent the irrigated and 850-mb downstream regions discussed in Section 3. Areas of regions 1 and 2 are 180,000 and 460,800 $\mathrm{km}^{2}$, respectively. Points labeled I and II represent locations of thermodynamic profiles explored in Section 3.3.

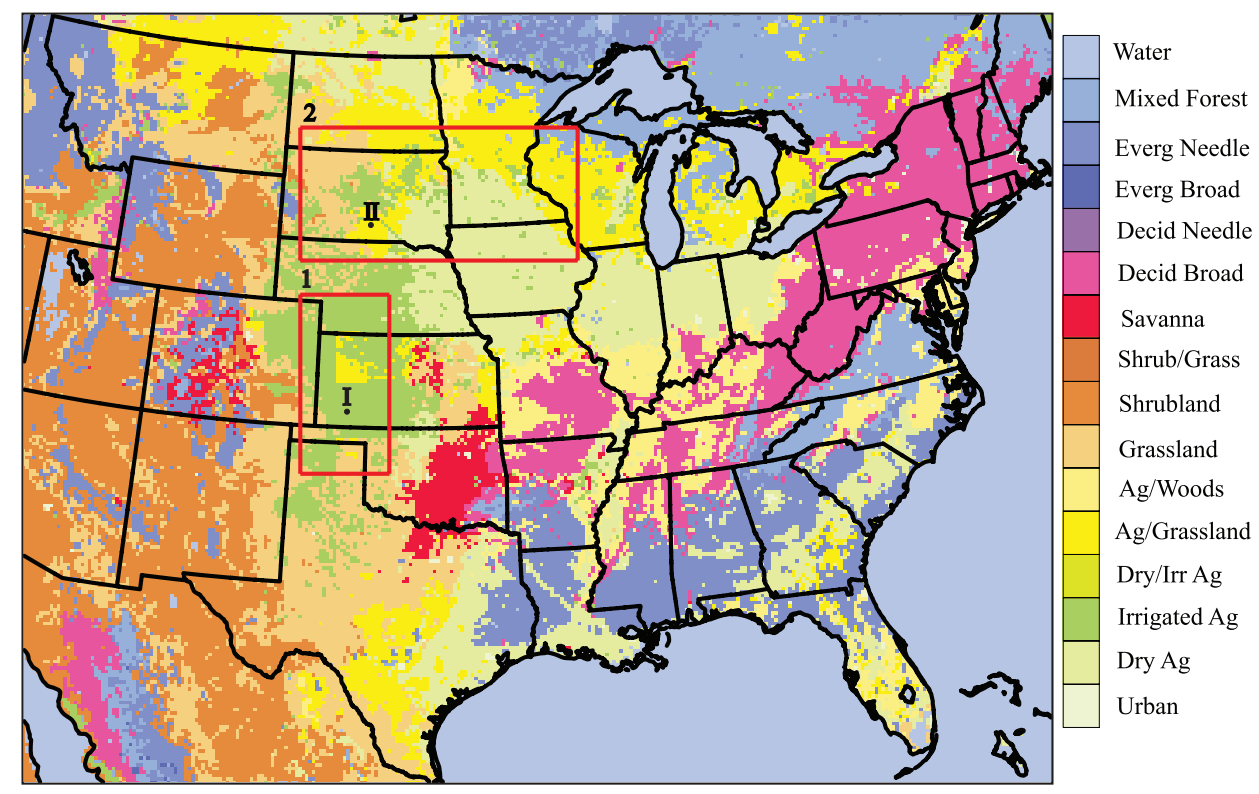

Initial conditions and 3-hourly boundary conditions for the simulations were provided by the 12-km North American Mesoscale Model (NAM, formerly known as the Eta model [34]). Although the NAM exhibits biases in moisture [35] and MCS propagation characteristics [35,36], we judged the 12-km grid spacing of NAM beneficial in forcing convection on the WRF grid, as compared to employing 
coarser datasets such as the 2.5-degree National Centers for Environmental Prediction (NCEP) global reanalysis [37]. With respect to the NAM dry bias, our WRF simulations produce sufficient precipitation over the 1-month period of our simulations. Both simulations were initialized on 1 May 2001 and integrated through 31 July 2001, encompassing a period chosen to be as climatologically average as possible. The time period was characterized by a near-neutral phase of ENSO (i.e., neither a positive nor a negative phase of the El Niño Southern Oscillation). Trier et al. [38] discuss the synoptic configuration and forcing mechanisms supporting convection throughout the period. Soil moisture content over the Great Plains soils was close to the climatic average, and the strength and position of the GPLLJ were typical for the summer period [38].

Both simulations used a modified 24-category, 30-second USGS land cover scheme to identify regions of irrigation (Figure 1). The land cover was modified with the specific intent of accentuating the possible impacts of irrigated agriculture overlying the Ogallala Aquifer in the Great Plains. The land cover scheme was altered in two ways: (1) grid cells containing any amount of irrigated land as identified by the original USGS land cover classification were set to contain only irrigated land; and (2) cells overlying the Ogallala aquifer that contained any amount of the land cover type "grassland/agriculture mosaic" were set to contain only irrigated land. The algorithm used in the original USGS land cover scheme identifies cells containing agriculture (irrigated and/or dry) and grassland as grassland/agriculture mosaic [39], so these land cover types overlying the Ogallala aquifer were changed to irrigated agriculture to maximize the areal extent of irrigation in the region. The overall size, shape, and position of the irrigated area within the Great Plains as shown in Figure 1 is quite similar to the observed properties of agriculture in the same region (see figure in [40]). All simulations employed the Noah land-surface model [41,42], which includes both bare soil and canopy evaporation, and transpiration from vegetation. Noah has been shown to overestimate latent heat flux somewhat in highly vegetated regions [43] and wet soil conditions [44], which potentially could lead to underestimating sensible heat flux and depleting soil moisture too rapidly. Despite this latent heat flux bias, Noah has nevertheless been used successfully in a variety of irrigation simulations ranging from a stand-alone configuration forced with atmospheric conditions [45] to fully-interactive mesoscale model simulations [20,21].

In the control simulation (CTL), soil moisture is replenished only by precipitation. The irrigation simulation (IRR) was identical to CTL, except that WRF was modified to represent irrigation. In the IRR simulation, beginning 15 May at 0000 UTC, the soil moisture content was set to field capacity in the top meter of soil for irrigated land cover types. This process was repeated every day thereafter at 0000 UTC until the end of the simulation. The top meter of the soil was set to field capacity in order to match the 1-m rooting depths used in the Noah land surface model. The two simulations (CTL and IRR) represent the two extremes of agriculture in the Great Plains, either presenting the agriculture with no added water or maintaining soil moisture at a state of maximum evaporative potential. Because of financial and water resource constraints, the amount of irrigation applied in the IRR simulation is admittedly unrealistic but represents the configuration of the near-maximum application of water physically possible. In addition to exaggering soil moisture in our approach, the modified land-cover classification also exaggerates the areal importance of irrigation. Our approach aims to evaluate the limiting-case impact of irrigation, and these simulations are not intended to match observations perfectly but rather to identify potential impacts of irrigation. Nonetheless, a comparison of the two simulations 
with observations is included below in Section 3.1. The data used for this comparison are from the North American Regional Reanalysis (NARR [46]) and the Climate Prediction Center United States Unified Precipitation dataset (CPC [47]).

\section{Simulation Results}

In order to assess the primary impacts of irrigation in the central United States, we focus on monthly mean differences between IRR and CTL simulations. The differences in soil moisture between CTL and IRR are most dramatic in the month of July. For this reason, results are presented only for July. Moreover, emphasis is placed on changes over the Great Plains and Midwest by showing these regions in the following figures.

\subsection{Precipitation}

Irrigation affects the radiation balance, water budget, and atmospheric flow, resulting in changes to the precipitation patterns and intensity throughout the Great Plains region (see the IRR and CTL simulated precipitation in Figure 2a,b, respectively). Figure 2c shows the mean July 2001 observed precipitation as represented in NARR. Identifiable in the reanalysis are three bands of precipitation: (1) one starting in west central Kansas and ending in central Missouri; (2) one running from northeastern Wyoming and ending in north central Minnesota; and (3) a weaker band starting in south central Nebraska and ending in western Illinois. In comparing Figure 2a,b with the observed precipitation in Figure 2c, it is apparent that both simulations roughly capture the regional distribution of precipitation, including the banded structures, although the placement of particular precipitation bands in the simulations is displaced northward relative to the NARR precipitation. In comparison with our 12-km (horizontal grid spacing) WRF simulations, the 32-km grid spacing of the NARR reanalysis indicates lower maximum precipitation values and a smoother representation of the precipitation field. Comparison with the higher-resolution $\left(0.25^{\circ} \times 0.25^{\circ}\right) \mathrm{CPC}$ gauge-derived dataset in Figure $2 \mathrm{~d}$ suggests that the lower maximum values in the NARR precipitation field are not a simple consequence of the coarser resolution, since the CPC maxima have similar magnitudes. We note substantial differences the two observationally-constrained datasets (Figure 2c,d), specifically that the CPC dataset indicates less precipitation coverage over the high-plains (regions including and northward of eastern Colorado and western Kansas) and more precipitation over Oklahoma, southeast Texas, and Louisiana. Some of these discrepancies may be attributable to the inability of a finite number of rain gauges to completely sample the precipitation field for a relatively small number of convective events.

Our simulation configuration is very similar to that used in the July 2001 WRF simulations of Trier et al. [38], which established the ability of the WRF model to perform credibly over this time period. Although the focus of our study is different, our simulated precipitation patterns are broadly consistent with their simulations. Furthermore, the level of agreement between WRF and the NARR precipitation patterns is typical for short (monthly to multi-monthly) simulations (e.g., [33]). The better agreement between our simulations and NARR as compared to the CPC data likely reflects the fact that both WRF and NARR employ the Eta model (as the underlying model component for NARR [46] and as forcing for the WRF simulations). The result that the WRF precipitation fields compare more favorably 
with NARR than with the CPC gauge product implies a level of consistency between WRF and the NAM output used for initial and boundary conditions but also suggests WRF is to some degree reproducing the biases inherent in the NAM model over this period.

Figure 2. Accumulated precipitation for the month of July for the (a) IRR and (b) CTL simulations, respectively; (c) July 2001 precipitation from the North American Regional Reanalysis (NARR); (d) July 2001 precipitation from the CPC U.S. Unified Precipiation dataset.

(a) July precipitation (IRR)

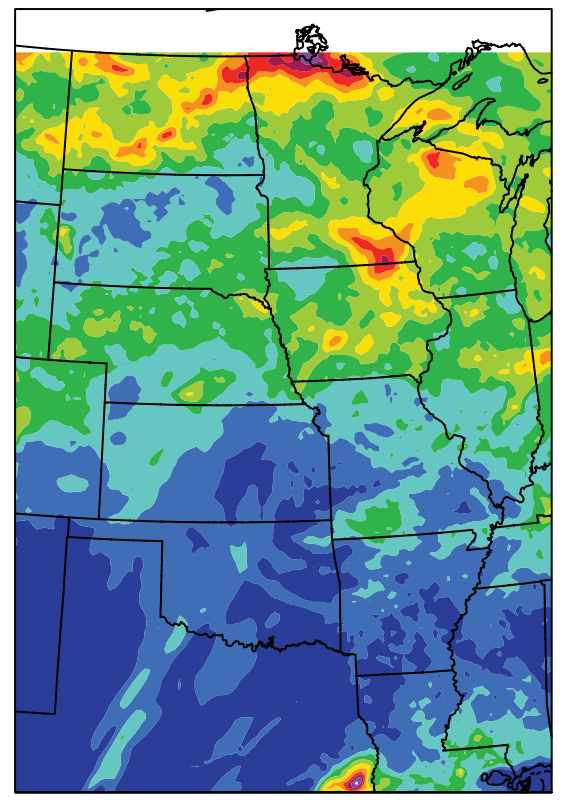

(b) July precipitation (CTL)

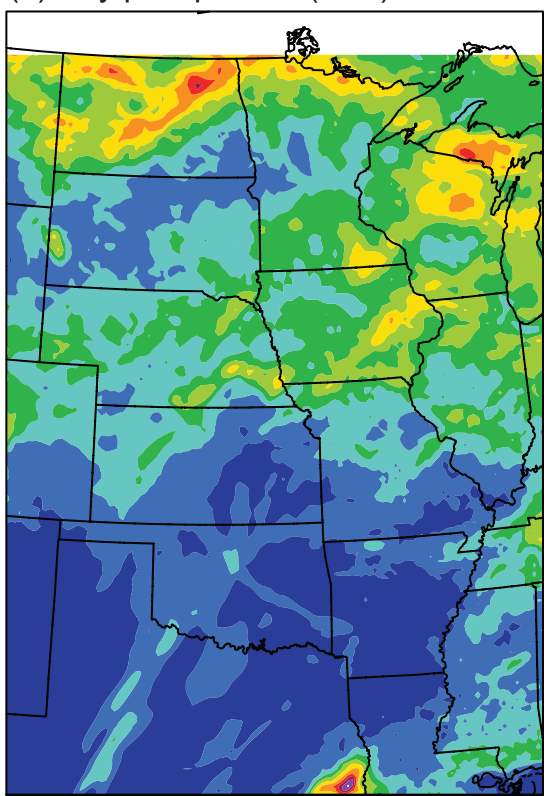

$[\mathrm{mm}]$

$\begin{array}{lllllllllll}0 & 40 & 80 & 120 & 160 & 200 & 240 & 280 & 320 & 360 & 400\end{array}$

(c) July 2001 precipitation (NARR)

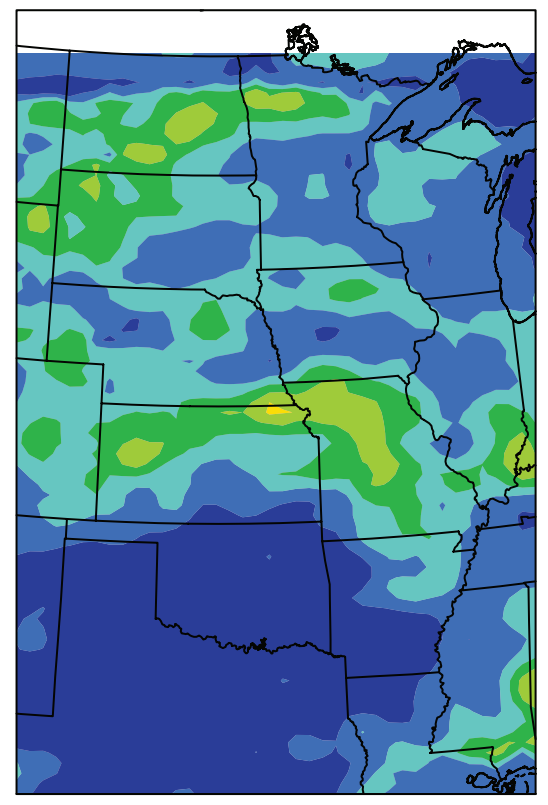

(d) July 2001 precipitation (CPC)

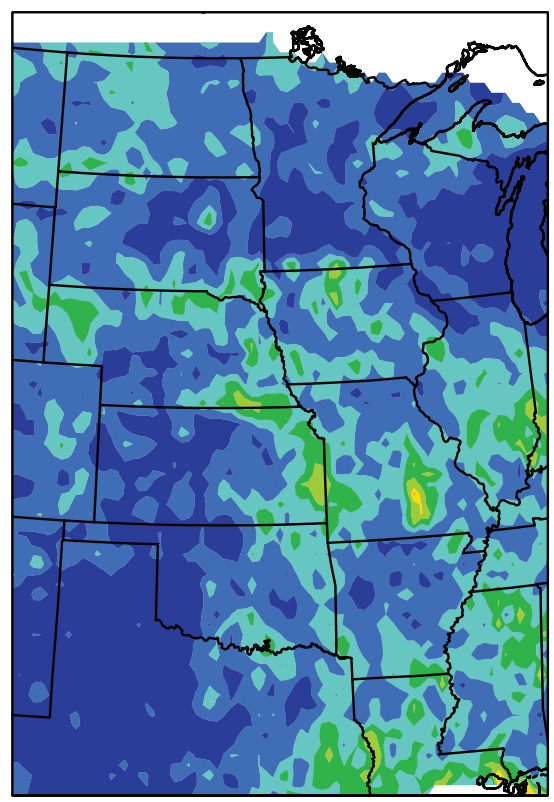

Little change in precipitation is evident over the irrigated regions themselves, but the areas downwind of the irrigated regions experience substantial increases in precipitation (Figure 3a,b; absolute and 
relative differences of $100 \mathrm{~mm}$ and $100 \%$, respectively). A comparison of Figure 2a,b indicate that irrigation preserves the spatial pattern of precipitation but increases the magnitude. The discussion in Section 3.5 addresses how the differences in precipitation shown in Figure 3 are related to changes in the regional flow pattern and moisture advection arising from irrigation.

Figure 3. Absolute (a) and relative (b) difference between the fields in Figure 2a,b (IRR-CTL).

(a) $P_{\text {IRR }}-P_{\text {CTL }}$

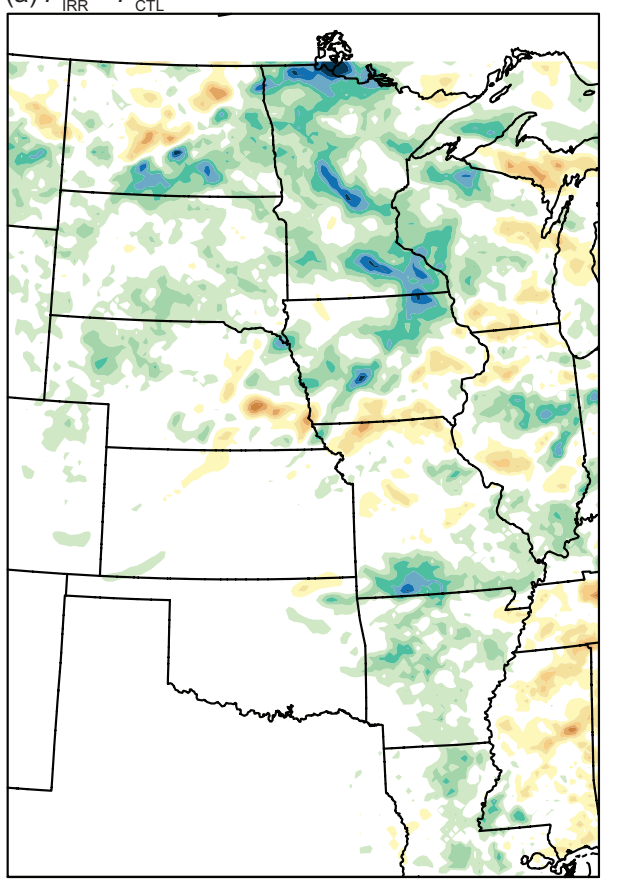

$\Delta \mathrm{P}[\mathrm{mm}]$ (b) $P_{\mathrm{IRR}}-P_{\mathrm{CTL}}$ (relative)

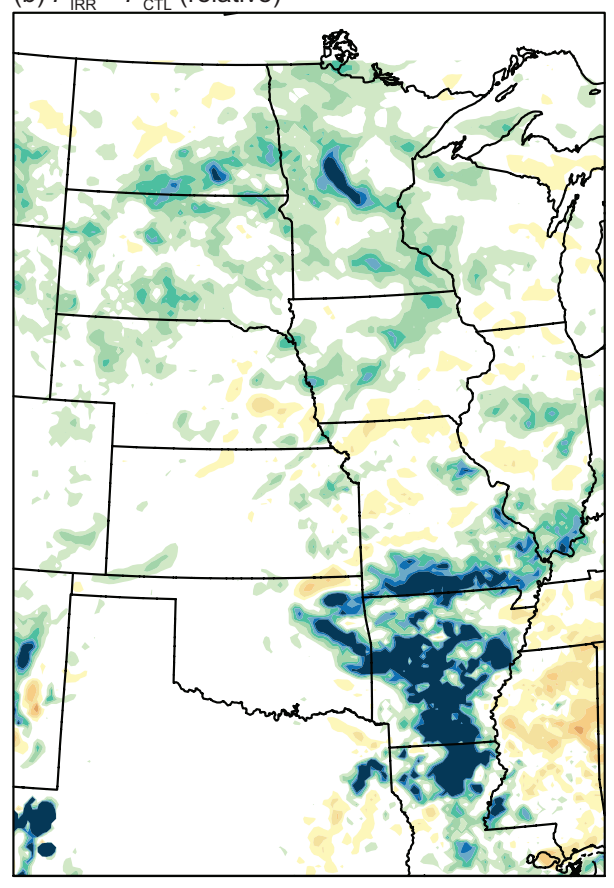

$\Delta \mathrm{P}[\%]$

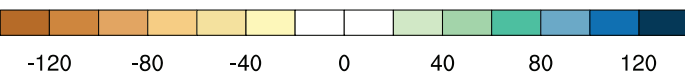

\subsection{Surface Radiation Budget}

The surface effects considered here are the alterations to the radiation budget and the surface energy budget. The net radiation is the balance of the incoming and outgoing radiative fluxes, given as:

$$
R_{n}=\epsilon L W_{d}-\sigma \epsilon T_{s}^{4}+(1-\alpha) S W
$$

where $S W$ is the shortwave radiation incident at the surface, $\alpha$ is albedo, $L W_{d}$ is the downwelling longwave radiation, $\sigma$ is the Stephan-Boltzmann constant, $\epsilon$ is the emissivity of the surface, and $T_{s}$ is the surface skin temperature in K. The emissivity and albedo are held constant for each land cover type across both simulations. Because emissivity and albedo are not represented as a function of soil moisture, it is assumed that differences in the radiation budget terms are based on other factors.

The net radiation is then allocated to the surface energy fluxes by:

$$
R_{n}=H+L E+G
$$

where $G$ is the soil heat flux, $H$ is turbulent sensible heat flux, and $L E$ is the turbulent latent heat flux. 
Figure 4. Differences in monthly-mean quantities between IRR (irrigated) and CTL (non-irrigated) simulations for the month of July. (a) Latent heat flux; (b) Sensible heat flux; (c) Evaporative fraction; (d) Percent difference in IRR net radiation with respect to the CTL simulation.
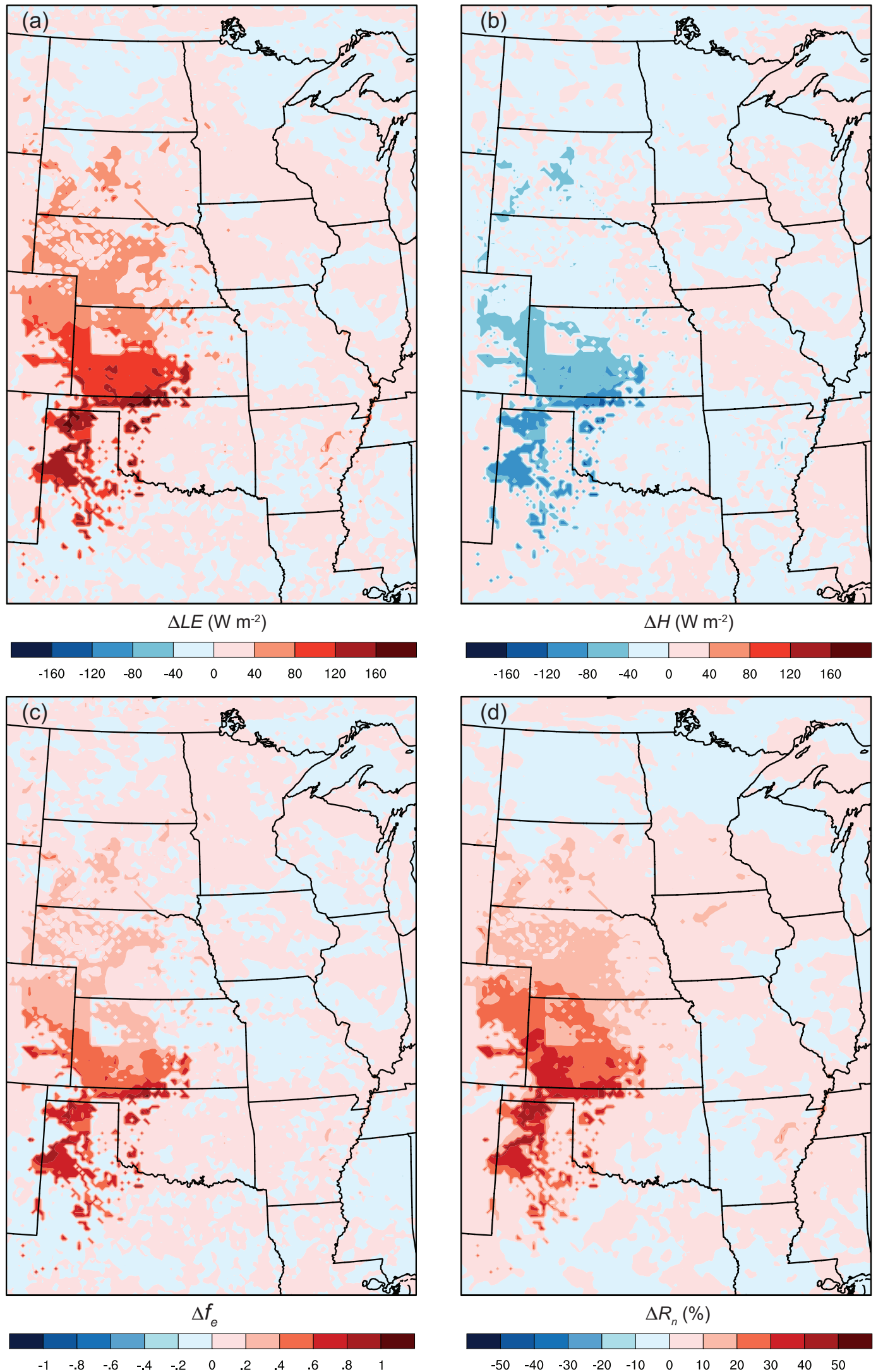
As shown in Figure 4a, the difference in hourly-averaged latent heat flux between the IRR and CTL cases for July is most dramatic over the irrigated regions of the Great Plains (region 1, Figure 1), and to a lesser extent to the north of the irrigated regions (region 2, Figure 1). Region 2, taken to be representative of the area downwind of the irrigated region, was determined based on the mean July 2001 low-level wind field. The quantity plotted in Figure $4 \mathrm{a}$ is simply the difference in monthly-mean latent heat flux between the irrigated and control simulations, i.e., $\Delta L E=L E_{I R R}-L E_{C T L}$. Within region 1, the increase in $L E$ ranged from approximately 100 to $400 \%$ as a result of increased soil moisture from the nearly-saturated irrigated land cover as compared to the drier conditions in the CTL simulation. The mean change in $L E$ over the irrigated region was an increase of $89 \%$ (Table 1 ). The increased $L E$ north of the irrigated region is due to increased soil moisture from precipitation (see Section 3.1), thereby increasing evapotranspiration and perhaps providing additional moisture for precipitation via local feedback and/or precipitation recycling. The mean change in daily $L E$ for region 2 was $10.3 \%$ (Table 1). The increased $L E$ results in a decrease in $H$ (Figure $4 \mathrm{~b}$ ), although smaller in absolute magnitude than the increase in $L E$. Table 1 shows that the mean change in $H$ over region 1 was a $64.3 \%$ decrease whereas in region 2 there was a $12.8 \%$ decrease in $H$. This change in sensible heat flux is driven by both a decrease in soil temperature due to the additional evaporative cooling accompanying irrigation (reflected in the difference in 2-m air temperatures shown in Figure 5) and a shift in the energy partitioning so that more of the $R_{n}$ is devoted to evaporation than to surface heating. The change in hourly-averaged July $G$ (not shown) is slightly positive, though small $\left(<1 \mathrm{~W} \cdot \mathrm{m}^{-2}\right.$, see Table 1$)$, over most of the irrigated regions.

Table 1. Comparison of elements of the surface energy balance, including radiative, turbulent, and ground fluxes, and temperature, for the two regions identified in Figure 1.

Differences are presented as both absolute and percent change relative to the control simulation.

\begin{tabular}{ccccccccc}
\hline \multirow{2}{*}{ Variable } & \multicolumn{3}{c}{ Region 1 } & \multirow{2}{*}{ Variable } & \multicolumn{3}{c}{ Region 2 } \\
\cline { 2 - 3 } & IRR & CTL & Diff. (\%) & & & IRR & CTL & Diff. (\%) \\
\hline$T(\mathrm{~K})$ & 302.3 & 307.0 & $-4.7(-1.5)$ & $T(\mathrm{~K})$ & 299.8 & 300.8 & $-1.0(-0.3)$ \\
$H\left(\mathrm{~W} \cdot \mathrm{m}^{-2}\right)$ & 20.6 & 57.7 & $-37.1(-64.3)$ & $H\left(\mathrm{~W} \cdot \mathrm{m}^{-2}\right)$ & 34.2 & 39.2 & $-5.0(-12.8)$ \\
$L E\left(\mathrm{~W} \cdot \mathrm{m}^{-2}\right)$ & 142.9 & 75.5 & $67.4(89.3)$ & & $L E\left(\mathrm{~W} \cdot \mathrm{m}^{-2}\right)$ & 112.1 & 101.6 & $10.5(10.3)$ \\
$G\left(\mathrm{~W} \cdot \mathrm{m}^{-2}\right)$ & 6.8 & 7.3 & $-0.5(-6.8)$ & $G\left(\mathrm{~W} \cdot \mathrm{m}^{-2}\right)$ & 8.1 & 8.6 & $-0.5(-5.8)$ \\
$\mathrm{LW}_{\text {up }}\left(\mathrm{W} \cdot \mathrm{m}^{-2}\right)$ & 458.8 & 488.9 & $-30.1(-6.2)$ & $\mathrm{LW}_{\text {up }}\left(\mathrm{W} \cdot \mathrm{m}^{-2}\right)$ & 433.6 & 439.7 & $-6.1(-1.4)$ \\
$\mathrm{LW}_{\text {down }}\left(\mathrm{W} \cdot \mathrm{m}^{-2}\right)$ & 359.9 & 364.0 & $-4.1(-1.1)$ & $\mathrm{LW}_{\text {down }}\left(\mathrm{W} \cdot \mathrm{m}^{-2}\right)$ & 353.4 & 352.5 & $0.9(0.3)$ \\
$\mathrm{LW}_{\text {net }}\left(\mathrm{W} \cdot \mathrm{m}^{-2}\right)$ & -98.9 & -124.9 & $26.0(20.8)$ & $\mathrm{LW}_{\text {net }}\left(\mathrm{W} \cdot \mathrm{m}^{-2}\right)$ & -80.2 & -87.2 & $7.0(8.0)$ \\
$\mathrm{SW}_{\text {net }}\left(\mathrm{W} \cdot \mathrm{m}^{-2}\right)$ & 268.5 & 264.2 & $4.3(1.6)$ & & $\mathrm{SW}_{\text {net }}\left(\mathrm{W} \cdot \mathrm{m}^{-2}\right)$ & 234.5 & 236.3 & $-1.8(-0.7)$ \\
$R_{\text {net }}\left(\mathrm{W} \cdot \mathrm{m}^{-2}\right)$ & 169.6 & 139.3 & $30.3(21.8)$ & $R_{\text {net }}\left(\mathrm{W} \cdot \mathrm{m}^{-2}\right)$ & 154.2 & 149.0 & $5.2(3.5)$ \\
\hline
\end{tabular}

The change in energy balance partitioning is investigated through the evaporative fraction $\left(f_{e}\right)$ :

$$
f_{e}=\frac{L E}{R_{n}-G}
$$


Figure 5. Differences in monthly-mean 2-m temperatures between IRR and CTL simulations for July. (a) Daily maximum temperature; (b) Daily minimum temperature; (c) Diurnal temperature range, the difference between maximum and minimum temperature. Contour units are $\mathrm{K}$, with the $-2 \mathrm{~K}$ contour represented by the dotted line.

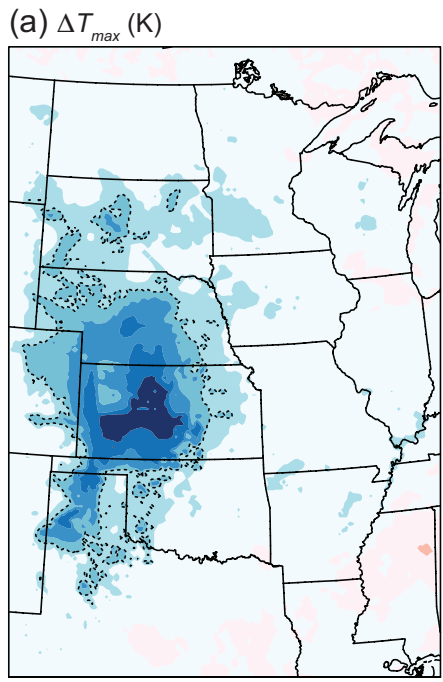

(b) $\Delta T_{\min }(\mathrm{K})$

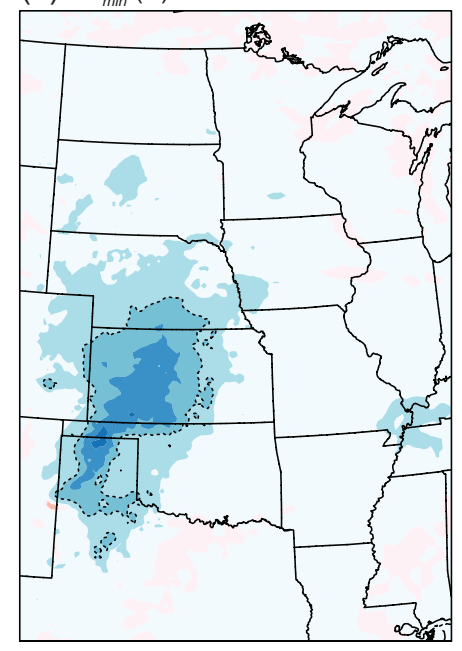

(c) $\Delta\left(T_{\max }-T_{\min }\right)(\mathrm{K})$

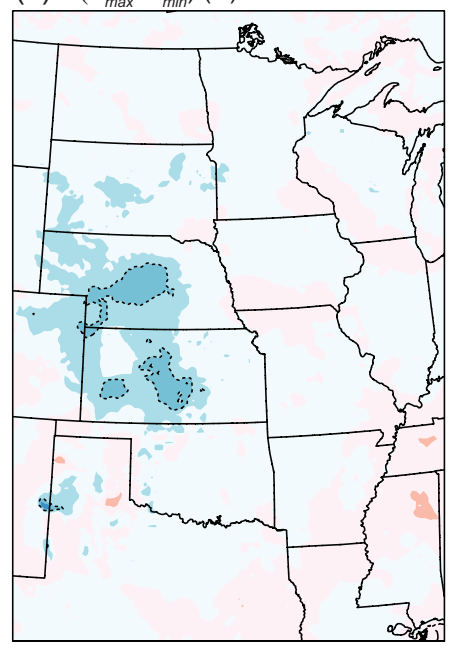

$\begin{array}{llllllllllllllll}-6 & -5 & -4 & -3 & -2 & -1 & 0 & 1 & 2 & 3 & 4 & 5 & 6\end{array}$

Figure $4 \mathrm{c}$ shows the daily averaged differences in evaporative fraction between IRR and CTL. A direct result of irrigation is to increase the fraction of energy employed to evaporate water, as opposed to being partitioned into sensible heat flux. The increase in evaporative fraction is especially prevalent in southern regions of the irrigated agriculture (e.g., the Texas panhandle to southern Kansas) where nearly $60 \%$ more energy is devoted to the evaporation of water relative to the non-irrigated CTL simulation.

In addition to the alteration of the surface energy partitioning, there are also changes in the near surface air temperatures due to irrigation. Our results confirm that irrigation leads to pronounced regional cooling. The differences in daily averaged maximum and minimum 2-m temperatures are shown in Figure 5a,b, respectively. Other research shows little agreement as to whether irrigation increases or decreases minimum temperature [48], but in our results irrigation decreases minimum temperature. Figure $5 \mathrm{c}$ depicts the change in daily averaged 2-m diurnal temperature range between IRR and CTL, with a decrease in diurnal temperature range accompanying irrigation. Mean reductions in 2-m temperature due to irrigation were $4.7 \mathrm{~K}$ within region 1 and $1.0 \mathrm{~K}$ in region 2 (Table 1). These decreases in mean temperature (Figure 5a-c and Table 1) are due to a combination of the increased evapotranspiration (in region 1) and advection of the cooler, moister air (in region 2). This decreased temperature results in a corresponding decrease in upwelling longwave radiation over much of the irrigated region $(-6.2 \%$ in region 1$)$. The lower troposphere is cooler, but the greater atmospheric emissivity associated with enhanced boundary layer moisture results in little change to the downwelling longwave flux at the surface (Table 1).

The alteration of the radiative and surface energy budgets due to irrigation results in increased net radiation over much of the Great Plains (Figure 4d). Over the irrigated regions, the increase in $L E$ and subsequent cooling of the surface reduces upwelling longwave radiation, resulting in an increase in $R_{n}$. 
The mean increase in $R_{n}$ over the irrigated region was $30.3 \mathrm{~W} \cdot \mathrm{m}^{-2}$ (Table 1 ), an increase of $21.8 \%$. Over region 2, there was a small change of $5.2 \mathrm{~W} \cdot \mathrm{m}^{-2}(3.5 \%)$.

Both regions exhibited small changes in net shortwave radiation. Because the albedo of the surface does not change, changes in shortwave radiation are assumed to be due only to changes in cloud cover. Changes in atmospheric water vapor also result in differences in downwelling shortwave radiation at the surface by changing the atmospheric absorption in the near-infrared. However, these modifications are minimal between the IRR and CTL cases in comparison to the differences arising from changes to cloud cover, and are thus ignored. Irrigation reduces the cloud cover over the irrigated region itself (an increase of net shortwave radiation of $1.6 \%$ in region 1; see Table 1) but slightly enhances cloud cover downstream of the irrigated region (a change of $-0.7 \%$ ). The Noah Land Surface Model does not enforce energy balance closure but instead reports the residual difference between the radiative fluxes and the heat fluxes. In all four cases (IRR and CTL, regions 1 and 2), the average residual for the energy balance is less than $1.5 \mathrm{~W} \cdot \mathrm{m}^{-2}$.

\subsection{Vertical Thermodynamic Structure}

Next, we wish to examine how the local changes in radiation and surface energy fluxes impact the thermodynamic properties of the atmosphere within and downwind of the irrigated region. For this purpose, we identified two points in Figure 1 to illustrate different effects that irrigation has on convective potential. The first point I is located in southwest Kansas, completely surrounded by irrigated agriculture. Point II is grassland and non-irrigated cropland in South Dakota, with irrigated agriculture predominantly to the south (although a small strip of irrigated agriculture lies to the north of point II).

Figure 6a,b show July-mean 2200 UTC (late afternoon) atmospheric soundings of temperature and dew point temperature at points I and II from the IRR and CTL simulations. Thermodynamic paths for surface-based parcels are overlaid for each profile. Over the irrigated region (Figure 6a), the surface temperatures are markedly different between the two simulations, with surface temperatures $6{ }^{\circ} \mathrm{C}$ cooler in the IRR simulation (solid and dashed lines, respectively). This sounding can be thought of as being roughly representative of the entire region 1 (Figure 1), where the IRR simulation in region 1 exhibits an increase in surface-based convective available potential energy (CAPE) from 209.8 to $654.7 \mathrm{~J} \cdot \mathrm{kg}^{-1}$ and convective inhibition (CIN) an increase from 74.9 to $160.7 \mathrm{~J} \cdot \mathrm{kg}^{-1}$ (Table 2). The increases of CAPE and CIN over the irrigated regions are obvious in Figure 7a,b. Because of the decreased sensible heat flux relative to the CTL simulation, the boundary layer in the IRR simulation is shallower and maintains a stronger capping inversion, which results in greater CIN (160.7 vs. $74.9 \mathrm{~J} \cdot \mathrm{kg}^{-1}$ ). (Note that the capping inversions present on any given day are smoothed out in these mean soundings and instead appear in the soundings as layers of enhanced stability.) On the other hand, having evaporated more water into the boundary layer and entraining less free-tropospheric dry air, the IRR boundary layer is moister than the CTL simulation (Figure 6a), which leads to greater values of CAPE (Figure 7a and Table 2), even given the cooler temperatures. Entrainment rate scales with $H$ [49] and directly affects the mixed-layer budgets of heat and moisture, leading to differences in CAPE. Therefore, more entrainment means a deeper boundary layer (approximately $3 \mathrm{~km}$ in Figure 6a) is drier than the shallower IRR boundary layer (approximately $1 \mathrm{~km}$ ). In the irrigated region, the increase in CIN over the entire diurnal period prohibits 
the additional CAPE from being realized in deep convective overturning. The smaller values of CIN seen in Figure $7 \mathrm{~b}$ over the area east of the irrigation (Iowa, Missouri, Arkansas, and Illinois) are associated with cooler 700-mb temperatures (not shown).

Figure 6. Skew-T log-P diagrams corresponding to (a) Point I and (b) Point II, as denoted in Figure 1. On each sounding are plotted monthly mean 2200 UTC simulated temperature and dew point temperature (both in ${ }^{\circ} \mathrm{C}$ ) for the CTL (solid black lines) and IRR (dotted black lines) simulations. Red lines represent thermodynamic paths of hypothetical surface-based parcels.
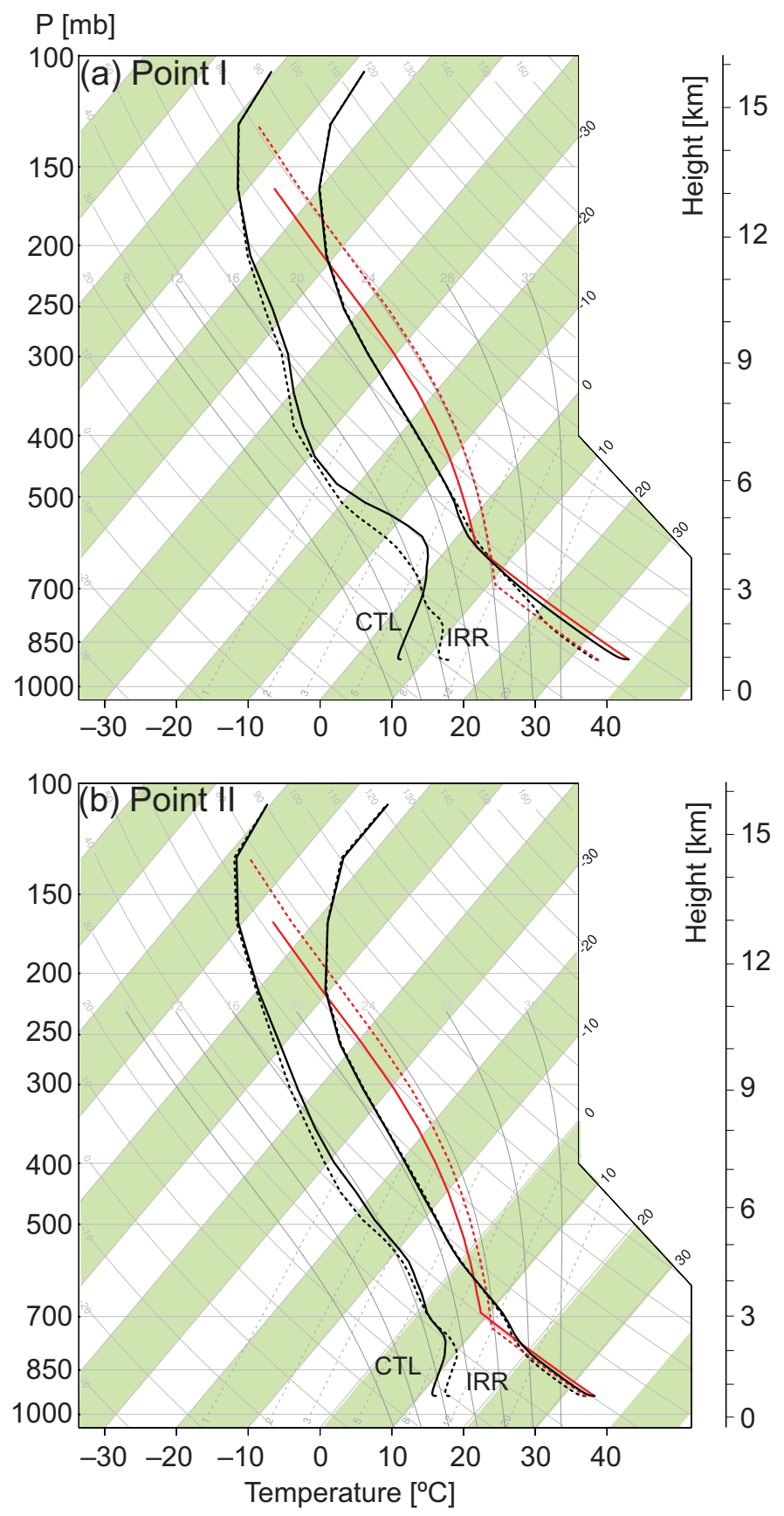
Table 2. As in Table 1 but for atmospheric quantities.

\begin{tabular}{|c|c|c|c|c|c|c|c|}
\hline \multirow{2}{*}{ Variable } & \multicolumn{3}{|c|}{ Region 1} & \multirow{2}{*}{ Variable } & \multicolumn{3}{|c|}{ Region 2} \\
\hline & IRR & CTL & Diff. (\%) & & IRR & CTL & Diff. (\%) \\
\hline$T_{a i r}(\mathrm{~K})$ & 301.9 & 306.6 & $-4.7(-1.5)$ & $T(\mathrm{~K})$ & 299.4 & 300.4 & $-1.0(-0.3)$ \\
\hline$W(\mathrm{~mm})$ & 27.6 & 25.5 & $2.1(8.2)$ & $W(\mathrm{~mm})$ & 31.7 & 30.9 & $0.9(2.8)$ \\
\hline $\operatorname{CAPE}\left(\mathrm{J} \cdot \mathrm{kg}^{-1}\right)$ & 654.7 & 209.8 & $444.8(212.0)$ & $\operatorname{CAPE}\left(\mathrm{J} \cdot \mathrm{kg}^{-1}\right)$ & 791.8 & 577.5 & $214.3(37.1)$ \\
\hline $\mathrm{CIN}\left(\mathrm{J} \cdot \mathrm{kg}^{-1}\right)$ & 160.7 & 74.9 & $85.8(114.5)$ & $\mathrm{CIN}\left(\mathrm{J} \cdot \mathrm{kg}^{-1}\right)$ & 103.8 & 122.3 & $-18.5(-15.1)$ \\
\hline $\mathrm{P}(\mathrm{mm})$ & 12.5 & 13.6 & $-1.1(-7.9)$ & $\mathrm{P}(\mathrm{mm})$ & 82.7 & 56.9 & $25.9(45.5)$ \\
\hline
\end{tabular}

Figure 7. Differences in monthly-mean (a) CAPE $\left(\mathrm{J} \cdot \mathrm{kg}^{-1}\right)$ and (b) CIN $\left(\mathrm{J} \cdot \mathrm{kg}^{-1}\right)$ between IRR and CTL simulations for the month of July.
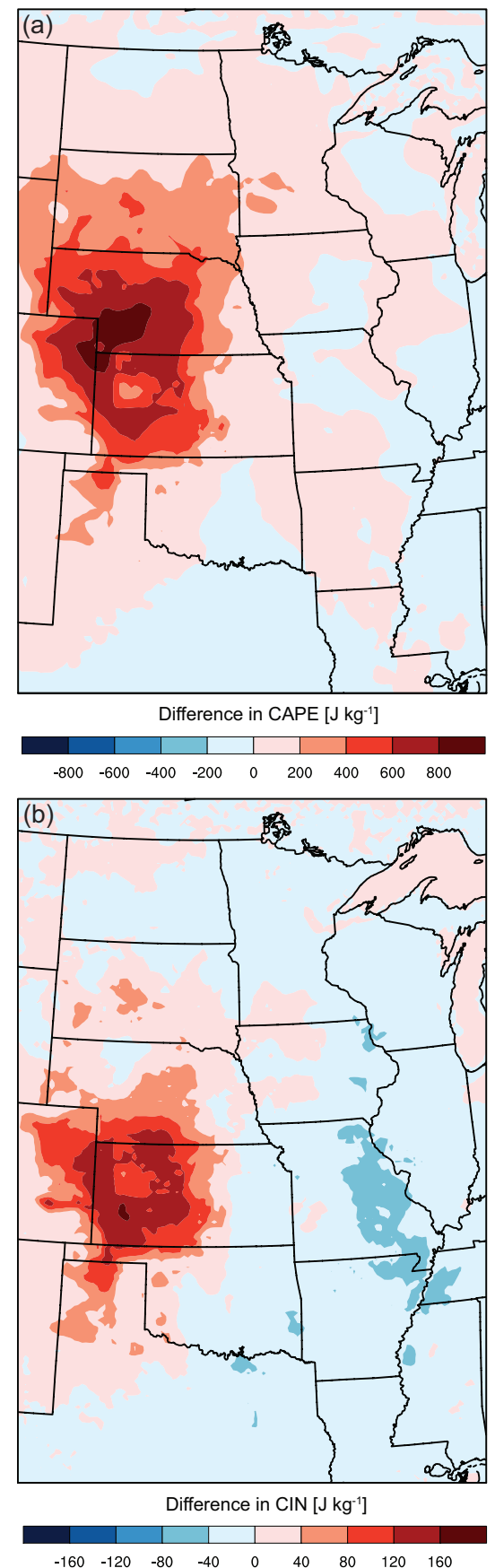

$\begin{array}{lllllllll}-160 & -120 & -80 & -40 & 0 & 40 & 80 & 120 & 160\end{array}$ 
The 2200 UTC sounding for point II (Figure 6b) shows that the temperature structure of the boundary layer and capping inversion are similar in both cases. The difference in parcel equivalent potential temperature $\left(\theta_{e}\right)$, therefore, is due to the difference in boundary-layer moisture. The similarity in boundary-layer depth (approximately $3 \mathrm{~km}$ in both scenarios) suggests that the difference in moisture can be attributed to differences in horizontal advection of moisture rather than local surface fluxes, which is consistent with the modest differences in surface fluxes over region 2 . The moister IRR boundary layer results in both a lower lifted condensation level (LCL) and the level of free convection (LFC) relative to the CTL simulation. The IRR simulation at point II is characteristic of region 2 with less CIN (103.0 J $\cdot \mathrm{kg}^{-1}$ in the irrigated case relative to 122.3 in CTL; Table 2). Table 2 shows that CAPE is increased in the region from $577.5 \mathrm{~J} \cdot \mathrm{kg}^{-1}$ in CTL to $791.8 \mathrm{~J} \cdot \mathrm{kg}^{-1}$ in IRR). Weaker CIN and enhanced CAPE (Table 2 and Figure 7a,b) suggest that, in the IRR simulation, convection across region 2 occurs more often and is likely to be stronger, relative to the CTL simulation.

Immediately to the north of the irrigated region and between regions 1 and 2, a zonal strip of decreased CIN is evident (Figure 7b). This decrease in CIN is associated with increased convergence at the exit region of the GPLLJ. This area also experiences an increase in precipitation, which is consistent with enhanced convergence in the region. Greater upward vertical motion associated with the stronger low-level convergence more quickly erodes the capping inversion relative to the CTL simulation, decreasing CIN. The simultaneous increase in CAPE and decrease in CIN over northern Nebraska, southern South Dakota, and southern Minnesota leads to higher precipitation totals, which will be discussed in Section 3.4.

\subsection{Lower-Atmospheric Flow}

Although we do not show it here, both WRF simulations capture well the placement of the Bermuda High and the GPLLJ present in the July 2001 850-mb NARR fields. Irrigation exerts a substantial effect on the regional flow in these simulations. Figure 8 shows hourly-averaged wind velocities, geopotential height differences, and percentage differences in wind speed at the $850-\mathrm{mb}$ level corresponding to the IRR and CTL simulations. Wind direction is mostly unchanged over and downstream of the irrigated region (which is why only the IRR wind vectors are shown). Differences in wind speed are apparent, however, and are associated with positive $850-\mathrm{mb}$ geopotential height anomalies (Figure 8). While Figure 8 shows the $850-\mathrm{mb}$ winds and associated fields averaged for all hours of the day, the same general adjustment to the nighttime fields, and thus the nocturnal GPLLJ, is evident. These positive height anomalies arise from the cooler temperatures in the lower atmosphere of the IRR simulation. The height anomalies are associated with a background pressure gradient acceleration to the southeast of the anomaly center (located in western Kansas) and an enhancement of the background pressure gradient to the northwest. This modulation of the regional-scale GPLLJ pressure pattern results in weaker flow southeast of the anomaly center and stronger flow to the northwest. The reduced wind speed over the bulk of Texas, Oklahoma, Kansas, and Missouri suggests reduced moisture transport from the GPLLJ. 
Figure 8. Composite of the mean July $850-\mathrm{mb}$ simulation results, illustrating the differences in wind and geopotential height structure between the CTL and IRR simulations. Vectors represent the 850-mb mean wind for the IRR simulation. The dark black contours indicate the mean difference in 850-mb geopotential height (IRR-CTL). The contour interval is $1 \mathrm{~m}$, with negative contours dashed. The color-shaded contours represent percent difference in IRR mean wind speed with respect to the CTL simulation. Red indicates the IRR flow is faster than the CTL flow; blue indicates the IRR flow is slower than the CTL flow.

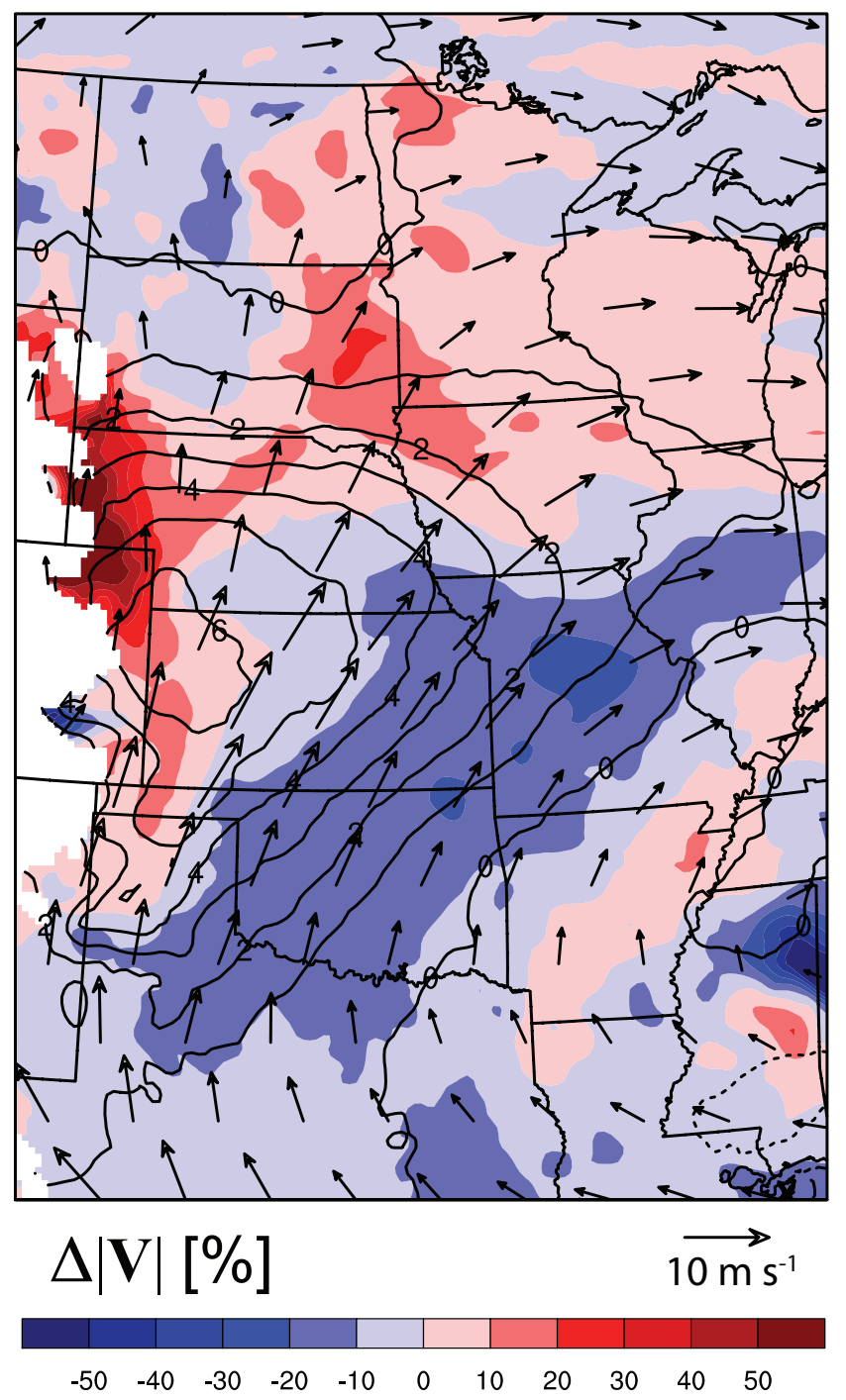

We interpret the positive 850 -mb height anomalies as a quasi-geostrophic (QG) response to the irrigation-driven cooling in the IRR simulation. This diabatic cooling (relative to the CTL simulation) is associated with an ageostrophic circulation that increases the net mass in the column and raises the lower-level geopotential heights [50,51]. The upper-level heights, which are not shown, exhibit weak height falls consistent with this diabatic QG response. From this relative diabatic cooling, we can infer (again, from QG theory) enhanced subsidence (or, more specifically, a reduction in the large-scale vertical velocity) over the irrigated region.

Figure 9 shows the hourly-averaged differences between IRR and CTL 700-mb vertical velocities. At the edge of the irrigated regions, especially in north Texas, anomalous mesoscale circulations are 
apparent by the strong horizontal gradient of vertical velocities, with negative differences over the irrigated regions and positive just outside the irrigated regions. The irrigated region itself is associated with enhanced downward vertical motion and divergence at low levels. To the south and east of region 1 (i.e., southeast Oklahoma, northwest Arkansas, eastern and central Texas, and southern Missouri), increased low-level convergence is evinced by the differential $850-\mathrm{mb}$ wind speeds (Figure 8).

Figure 9. Difference in monthly-mean 700-mb vertical velocities between the IRR and CTL simulations for the month of July $\left(\mathrm{m} \cdot \mathrm{s}^{-1}\right)$.

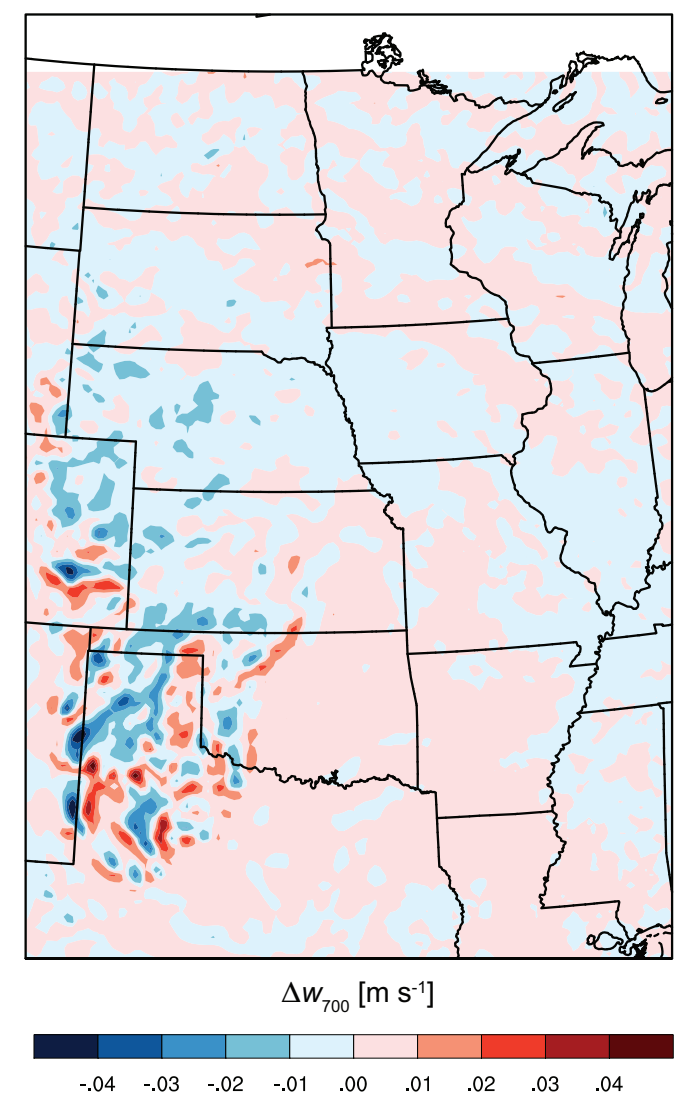

The difference between the IRR and CTL cases in hourly-averaged precipitable water $(W)$ is shown in Figure 10a,b. It is noticeable that moisture in the atmosphere increases (2.1 $\mathrm{mm}(8.2 \%)$, see Table 2$)$ over the irrigated regions and downstream $(0.9 \mathrm{~mm}$ or $2.8 \%)$ of these areas in the vicinity of the Dakotas and Minnesota. This difference is caused by increased local evaporation over the irrigated areas and the transport of the moister boundary layer air to the regions immediately downstream. The precipitable water is greater in both locations, despite a weakened GPLLJ in the IRR simulation.

To the south of the irrigated areas, it is evident that the slower wind speeds result in less moisture transport from the Gulf of Mexico (Figures 8 and 11). However, this reduced moisture advection is more than made up by horizontal transport of the additional moisture via evaporation from the irrigated cropland. These competing effects ultimately result in greater amounts of precipitable water over both the irrigated regions and the downstream areas (Figure 10). 
Figure 10. Differences in monthly-mean precipitable water (PW) between the IRR and CTL simulations for the month of July. (a) Absolute difference (mm); (b) Relative difference (\%).
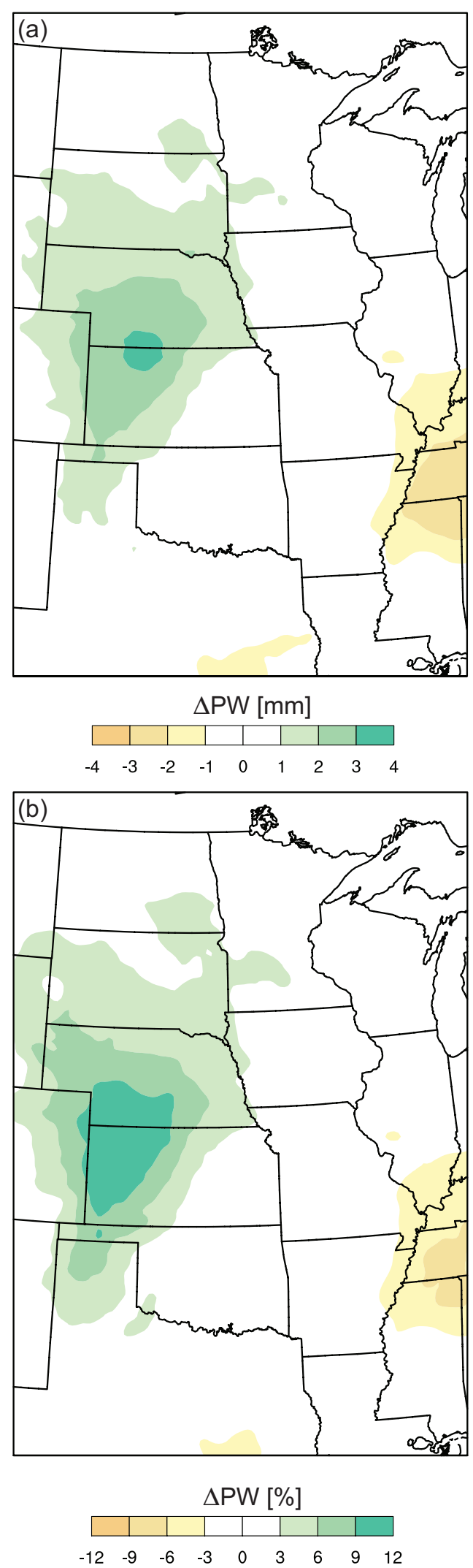
Figure 11. Difference in monthly-mean vertically-integrated horizontal moisture advection (IRR-CTL) for the month of July.

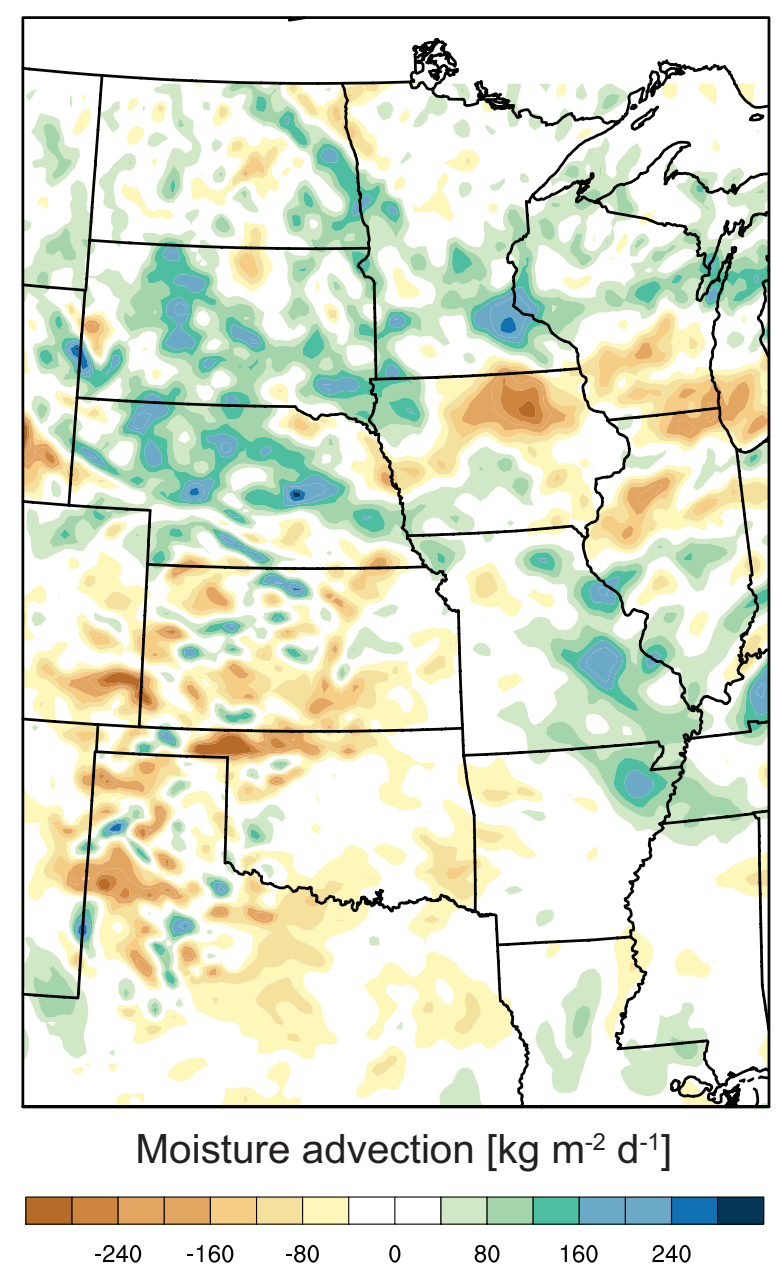

\subsection{Differences in Precipitation Behavior}

As seen previously in Figure 3, irrigation causes very little change to precipitation over the irrigated regions themselves. However, a comparison of precipitation differences between the simulations (Figure 3) with the regional flow pattern in Figure 8 shows that the majority of the differences in precipitation occur just downwind of the irrigated region (the Dakotas, Minnesota, Iowa, and Wisconsin) and to the southeast of regions 1 and 2 (Missouri, Arkansas, and Louisiana). Both areas of increased precipitation are associated with positive moisture advection anomalies (Figure 11). Precipitation differences caused by irrigation subsequently influence the radiation balance and water budgets, especially in regions downstream of the irrigated land use areas, as evident in Figure 4. These areas to the southeast of regions 1 and 2 are also affected by the change in GPLLJ; however, for brevity we have restricted our current analysis to only the irrigated region and those areas immediately downstream. Clearly, regions to the southeast, as well as regions further east of the area shown, require additional analysis.

Figure 12a,b show the time-series of precipitation over regions 1 and 2 . It is evident in both simulations that the number of precipitation events does not change, most likely because convective initiation tends to be dominated by large-scale or mesoscale forcing rather than by local effects. 
We feel this result is physically sound but also acknowledge that it may be particular to the flow regime experienced during the summertime over the Great Plains. Although the number of events does not change, the intensity of the precipitation in the IRR simulation is much greater than the CTL precipitation. By the end of the month, the enhancement in downstream precipitation in the IRR simulation is $25.9 \mathrm{~mm}(45.5 \%$; Table 2). This difference is due to the increase in precipitable water and instability, as evinced by higher values of CAPE. The number of convective events over the irrigated region is small, and the change in total precipitation over this region is negligible $(-1.1 \mathrm{~mm}$, Table 2$)$.

Figure 12. Spatially-averaged precipitation time-series for (a) region 1 and (b) region 2 for the CTL and IRR simulations. The mean precipitation for each region listed in Table 2 corresponds to the accumulated precipitation from these time series.

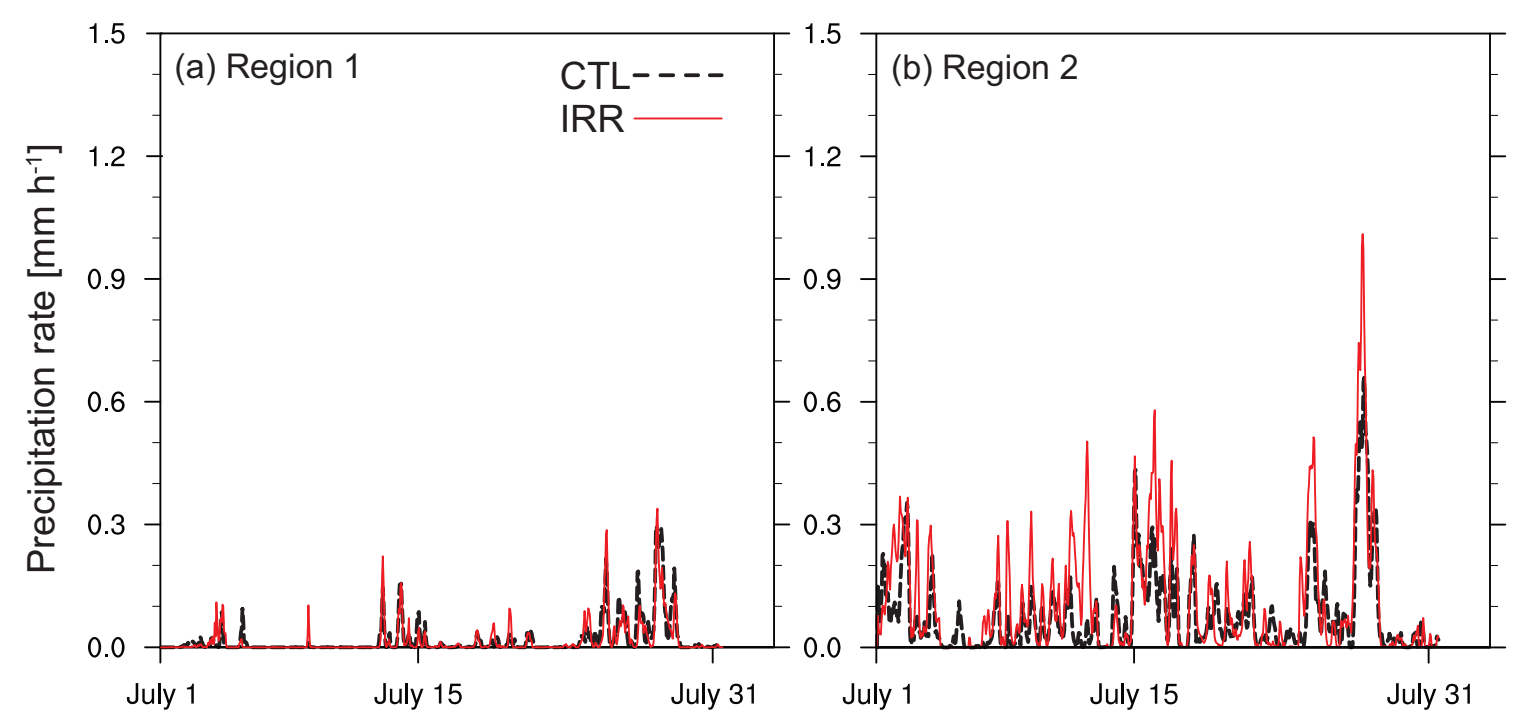

\section{Discussion and Conclusions}

The results presented here confirm those of previous studies that extreme values of irrigation alter the surface energy balance, boundary-layer budgets of heat and moisture, and precipitation. Little difference in precipitation occurs over the irrigated region itself, but the alterations brought about by irrigation are able to affect precipitation patterns downstream from the irrigated region.

The most original aspect of this research lies in a better understanding of the influence of irrigation on the regional circulation. The irrigated regions exhibit a preferential cooling of the surface and boundary layer associated with enhanced evapotranspiration. Irrigation leads to an increase in the 850-mb geopotential height over the irrigated region, a behavior we interpret as a quasi-geostrophic response to the cooling brought about by irrigation. This positive $850-\mathrm{mb}$ anomaly weakens the GPLLJ to the east and southeast of the height anomaly and strengthens the jet to the north and northeast of the anomaly, thus influencing the regional circulation.

The modified regional circulation is manifested as a decrease in wind speed throughout much of the Great Plains. Despite the weaker GPLLJ flow, because of the enhanced moisture source from irrigation, moisture advection is predominantly positive over the area downstream of the irrigated region (Figure 11). One of the atmospheric responses to differences in diabatic heating brought about by 
irrigation is enhanced downward motion at lower levels. The enhanced subsidence and lower-atmosphere divergence tends to strengthen the secondary circulations already present at boundaries between different land-use types. Meanwhile, stronger upward vertical velocity develops near these boundaries, often enhancing precipitation. The importance of these secondary circulations in reference to heterogeneous land cover and soil moisture is consistent with previous studies (e.g., [23,24,52]). Similar changes to the flow patterns were found to occur during the flood of 1993, as evidenced by the modeling study performed by Paegle et al. [27], although none of the previous research formally established the mechanism responsible for modifying the flow. Our QG interpretation of the irrigation-cooling is one such explanation.

Increases in CAPE over the irrigated regions are transported downstream of the irrigated regions, where they serve to enhance convective precipitation. In the simulations, large-scale forcing dominates the initiation of the convective systems, and irrigation does not change the actual number of precipitation events. The amount of precipitation per event, however, increases in the simulation with irrigation. This result suggests that precipitation events downstream of irrigated regions may be more likely to produce extreme precipitation events such as river flooding and flash-flooding incidents. This conclusion is in agreement with the observational study of river discharge rates by Kustu et al. [53] and the historical study by DeAngelis et al. [10], showing that precipitation totals have increased in the northern plains and the Midwest over the past 50 years, a period that coincides with increased use of irrigation.

Although this set of simulations has demonstrated many of the climatic mechanisms that irrigation is capable of producing, it is important to note that this is a sensitivity study serving to illustrate the limiting-case effects of irrigation. The results from either simulation presented within this paper are not intended to perfectly match observations from the Summer of 2001 in the U.S., and to some degree the agreement with observations is limited by the NAM output used as initial and boundary conditions for the WRF simulations. The simulation period of July 2001 was chosen becase it is climatologically average, whereas individual years may depart substantially from climatology. We speculate that the potential effects of irrigation would be dampened during wet years and strengthened during dry years. We speculate that the tendency of Noah to overestimate latent heat flux in wet soil moisture conditions may slightly overestimate the impact of irrigation in our simulations. The results presented here are intended to show the potential impacts of irrigation for the climatological average and to enable us to explore the mechanisms underlying land-atmosphere, boundary layer, and precipitation processes associated with irrigation. Other recent studies impose more modest values of irrigation, but we chose our approach to produce as strong a signal as possible in order to gain insight into possible mechanisms behind irrigation-induced changes to the GPLLJ.

Because of the limiting-case nature of the experimental design, the amount of irrigation applied in the IRR simulation was very large. The majority of the irrigated grid cells accumulated between 0.05 and $0.3 \mathrm{~m}$ of simulated irrigation during July. The total irrigation applied depended predominantly upon soil type and rainfall. This magnitude of irrigation is unrealistic, given a typical amount applied over an entire growing season (mid-May to mid-October) ranges from 0.2 to $0.3 \mathrm{~m}$ for corn and approximately $0.2 \mathrm{~m}$ for soy beans, with a substantial fraction of that amount being applied in August and September [54]. 
Irrigation complicates how we interpret the historical climate observations over the Great Plains. The cooling of the lower atmosphere from additional evapotranspiration has the ability to regionally mask the temperature change due to increased global greenhouse gases. For instance, the temperatures in some irrigated regions of Nebraska have decreased in recent decades [55]. This is in agreement with many other studies investigating the effects of irrigation on temperature and the radiation balance (e.g., $[11,26,54,56])$. Although the amount of irrigation imposed in the present study is unrealistic, the magnitude of the irrigation impacts confirms that irrigation is a first-order climate forcing on the regional scale with respect to temperature [1]. This suggests, as discussed by Brunsell et al. [3], the amount of heating expected due to the increase of greenhouse gases [57] may not as strongly influence regions like the western Great Plains. However, at least over the Kansas portion of the central Great Plains, the amount of irrigated cropland largely levelled off in the 1980s, and the total amount of irrigation has actually experienced a slow decrease (because of a combination of declining water table levels and more efficient tillage practices) [58]. These local trends are consistent with the national trends in total irrigated farmland and irrigation and over the entire United States [59,60]. Since current rates of extraction from the Ogallala aquifer are unsustainable [61], this offset of warming may not be continued into the future.

\section{Acknowledgments}

This work was supported under the National Science Foundation EPSCoR program (NSF EPS-0553722 and EPS-0919443), KAN0061396/KAN0066263, and Department of Energy Grant DE-SC0005359. We wish to thank Melissa Bukovsky and Johannes Feddema for their insights and advice. We appreciate the insights from two anonymous reviewers, which greatly improved the content and presentation of the paper. Thanks to Carly fish for helping edit the manuscript. CPC U.S. Unified Precipitation data provided by the NOAA/OAR/ESRL PSD, Boulder, CO, USA, from their Web site.

\section{Author Contributions}

This research is the culmination of David B. Huber's M.Sc. thesis. David B. Huber performed all simulations, the bulk of the analysis, and wrote the manuscript draft. David B. Mechem oversaw the project and revised the manuscript for publication. Nathaniel A. Brunsell aided in writing and interpretation of simulation results.

\section{Conflicts of Interest}

The authors declare no conflicts of interest.

\section{References}

1. Hansen, J.; Sato, M.; Ruedy, R.; Nazarenko, L.; Lacis, A.; Schmidt, G.; Russell, G.; Aleinov, I.; Bauer, M.; Bauer, S.; et al. Efficacy of climate forcings. J. Geophys. Res. Atmos. (1984-2012) 2005, 110, doi:10.1029/2005JD005776.

2. Pielke, R.A. Influence of the spatial distribution of vegetation and soils on the prediction of cumulus convective rainfall. Rev. Geophys. 2001, 39, 151-177. 
3. Brunsell, N.A.; Jones, A.R.; Jackson, T.; Feddema, J. Seasonal trends in air temperature and precipitation in IPCC AR4 GCM output for Kansas, USA: Evaluation and implications. Int. J. Climatol. 2010, 30, 1178-1193.

4. Koster, R.D.; Dirmeyer, P.A.; Guo, Z.; Bonan, G.; Chan, E.; Cox, P.; Gordon, C.; Kanae, S.; Kowalczyk, E.; Lawrence, D.; et al. Regions of strong coupling between soil moisture and precipitation. Science 2004, 305, 1138-1140.

5. Brunsell, N. Characterization of land-surface precipitation feedback regimes with remote sensing. Remote Sens. Environ. 2006, 100, 200-211.

6. Jones, A.; Brunsell, N. A scaling analysis of soil moisture-precipitation interactions in a regional climate model. Theor. Appl. Climatol. 2009, 98, 221-235.

7. Jones, A.R.; Brunsell, N.A. Energy balance partitioning and net radiation controls on soil moisture-precipitation feedbacks. Earth Interact. 2009, 13, 1-25.

8. Seneviratne, S.I.; Corti, T.; Davin, E.L.; Hirschi, M.; Jaeger, E.B.; Lehner, I.; Orlowsky, B.; Teuling, A.J. Investigating soil moisture-Climate interactions in a changing climate: A review. Earth-Sci. Rev. 2010, 99, 125-161.

9. Barnston, A.G.; Schickedanz, P.T. The effect of irrigation on warm season precipitation in the southern Great Plains. J. Clim. Appl. Meteorol. 1984, 23, 865-888.

10. DeAngelis, A.; Dominguez, F.; Fan, Y.; Robock, A.; Kustu, M.D.; Robinson, D. Evidence of enhanced precipitation due to irrigation over the Great Plains of the United States. J. Geophys. Res. 2010, 115, doi:10.1029/2010JD013892.

11. Adegoke, J.O.; Pielke Sr, R.A.; Eastman, J.; Mahmood, R.; Hubbard, K.G. Impact of irrigation on midsummer surface fluxes and temperature under dry synoptic conditions: A regional atmospheric model study of the US High Plains. Mon. Weather Rev. 2003, 131, 556-564.

12. Lobell, D.B.; Bonfils, C. The effect of irrigation on regional temperatures: A spatial and temporal analysis of trends in California, 1934-2002. J. Clim. 2008, 21, 2063-2071.

13. Eltahir, E.A. A soil moisture-rainfall feedback mechanism: 1. Theory and observations. Water Resour. Res. 1998, 34, 765-776.

14. Betts, A.; Ball, J.; Beljaars, A.; Miller, M.; Viterbo, P. Coupling between Land-Surface Boundary-Layer Parameterizations and Rainfall on Local and Regional Scales: Lessons from the Wet Summer of 1993. In Proceedings of the Preprints AMS Fifth Conference on Global Change Studies, 23-28 January 1994; pp. 174-181.

15. Betts, A.K.; Ball, J.H.; Beljaars, A.; Miller, M.J.; Viterbo, P.A. The land surface-atmosphere interaction: A review based on observational and global modeling perspectives. J. Geophys. Res. Atmos. (1984-2012) 1996, 101, 7209-7225.

16. Qian, Y.; Huang, M.; Yang, B.; Berg, L.K. A modeling study of irrigation effects on surface fluxes and land-air-cloud interactions in the Southern Great Plains. J. Hydrometeorol. 2013, doi:10.1175/JHM-D-12-0134.1.

17. Findell, K.L.; Eltahir, E.A. Atmospheric controls on soil moisture-boundary layer interactions. Part I: Framework development. J. Hydrometeorol. 2003, 4, 552-569.

18. Findell, K.L.; Eltahir, E.A. Atmospheric controls on soil moisture-boundary layer interactions. Part II: Feedbacks within the continental United States. J. Hydrometeorol. 2003, 4, 570-583. 
19. Moore, N.; Rojstaczer, S. Irrigation's influence on precipitation: Texas High Plains, USA. Geophys. Res. Lett. 2002, 29, doi:10.1029/2002GL014940.

20. Harding, K.J.; Snyder, P.K. Modeling the atmospheric response to irrigation in the Great Plains. Part I: General impacts on precipitation and the energy budget. J. Hydrometeorol. 2012, 13, 1667-1686.

21. Harding, K.J.; Snyder, P.K. Modeling the atmospheric response to irrigation in the Great Plains. Part II: The precipitation of irrigated water and changes in precipitation recycling. J. Hydrometeorol. 2012, 13, 1687-1703.

22. Segal, M.; Arritt, R. Nonclassical mesoscale circulations caused by surface sensible heat-flux gradients. Bull. Am. Meteorol. Soc. 1992, 73, 1593-1604.

23. Garcia-Carreras, L.; Parker, D.J.; Taylor, C.M.; Reeves, C.E.; Murphy, J.G. Impact of mesoscale vegetation heterogeneities on the dynamical and thermodynamic properties of the planetary boundary layer. J. Geophys. Res. Atmos. (1984-2012) 2010, doi:10.1029/2009JD012811.

24. Lohar, D.; Pal, B. The effect of irrigation on premonsoon season precipitation over South West Bengal, India. J. Clim. 1995, 8, 2567-2570.

25. De Ridder, K.; Gallée, H. Land surface-induced regional climate change in southern Israel. J. Appl. Meteorol. 1998, 37, 1470-1485.

26. Kueppers, L.M.; Snyder, M.A.; Sloan, L.C. Irrigation cooling effect: Regional climate forcing by land-use change. Geophys. Res. Lett. 2007, doi:10.1029/2006GL028679.

27. Paegle, J.; Mo, K.C.; Nogués-Paegle, J. Dependence of simulated precipitation on surface evaporation during the 1993 United States summer floods. Mon. Weather Rev. 1996, 124, 345-361.

28. Cook, K.H.; Vizy, E.K.; Launer, Z.S.; Patricola, C.M. Springtime intensification of the Great Plains low-level jet and Midwest precipitation in GCM simulations of the twenty-first century. J. Clim. 2008, 21, 6321-6340.

29. Skamarock, W.C.; Klemp, J.B.; Dudhia, J.; Gill, D.O.; Barker, D.M.; Wang, W.; Powers, J.G. A Description of the Advanced Research WRF Version 2. Technical Report, NCAR/TN-468+STR, National Center for Atmospheric Research: Boulder, CO, USA, 2005.

30. Kain, J.S. The Kain-Fritsch convective parameterization: An update. J. Appl. Meteorol. 2004, 43, 170-181.

31. Noh, Y.; Cheon, W.; Hong, S.; Raasch, S. Improvement of the K-profile model for the planetary boundary layer based on large eddy simulation data. Boundary-Lay. Meteorol. 2003, 107, 401-427.

32. Liu, C.; Moncrieff, M.W.; Grabowski, W.W. Explicit and parameterized realizations of convective cloud systems in TOGA COARE. Mon. Weather Rev. 2001, 129, 1689-1703.

33. Bukovsky, M.S.; Karoly, D.J. Precipitation simulations using WRF as a nested regional climate model. J. Appl. Meteorol. Climatol. 2009, 48, 2152-2159.

34. Black, T.L. The new NMC mesoscale Eta model: Description and forecast examples. Weather Forecast. 1994, 9, 265-278. 
35. Wang, S.Y.; Chen, T.C.; Taylor, S.E. Evaluations of NAM forecasts on midtropospheric perturbation-induced convective storms over the US northern plains. Weather Forecast. 2009, doi:10.1175/2009WAF2222185.1.

36. Yost, C. Investigation into a Displacement Bias in Numerical Weather Prediction Model Forecasts of Mesoscale Convective Systems. Master's Thesis, Colorado State University, Fort Collins, CO, USA, 2013.

37. Kalnay, E.; Kanamitsu, M.; Kistler, R.; Collins, W.; Deaven, D.; Gandin, L.; Iredell, M.; Saha, S.; White, G.; Woollen, J.; et al. The NCEP/NCAR 40-year reanalysis project. Bull. Am. Meteorol. Soc. 1996, 77, 437-471.

38. Trier, S.; Davis, C.; Ahijevych, D. Environmental controls on the simulated diurnal cycle of warm-season precipitation in the continental United States. J. Atmos. Sci. 2010, 67, 1066-1090.

39. Anderson, J.R. A Land Use and Land Cover Classification System for Use with Remote Sensor Data; US Government Printing Office: Washington, DC, USA, 1976.

40. McGuire, V.L.; Johnson, M.R.; Schieffer, R.L.; Stanton, J.; Sebree, S.K.; Verstraeten, I.M. Water in Storage and Ground-Water Management Approaches, High Plains Aquifer, 2000; Geological Survey (USGS): Reston, VA, USA, 2002.

41. Chen, F.; Dudhia, J. Coupling an advanced land surface-hydrology model with the Penn State-NCAR MM5 modeling system. Part I: Model implementation and sensitivity. Mon. Weather Rev. 2001, 129, 569-585.

42. Ek, M.; Mitchell, K.; Lin, Y.; Rogers, E.; Grunmann, P.; Koren, V.; Gayno, G.; Tarpley, J. Implementation of Noah land surface model advances in the National Centers for Environmental Prediction operational mesoscale Eta model. J. Geophys. Res. Atmos. (1984-2012) 2003, doi:10.1029/2002JD003296.

43. Hong, S.; Lakshmi, V.; Small, E.E.; Chen, F.; Tewari, M.; Manning, K.W. Effects of vegetation and soil moisture on the simulated land surface processes from the coupled WRF/Noah model. J. Geophys. Res. Atmos. (1984-2012) 2009, doi:10.1029/2008JD011249.

44. Chen, F.; Mitchell, K.; Schaake, J.; Xue, Y.; Pan, H.L.; Koren, V.; Duan, Q.Y.; Ek, M.; Betts, A. Modeling of land surface evaporation by four schemes and comparison with FIFE observations. J. Geophys. Res. Atmos. (1984-2012) 1996, 101, 7251-7268.

45. Ozdogan, M.; Rodell, M.; Beaudoing, H.K.; Toll, D.L. Simulating the effects of irrigation over the United States in a land surface model based on satellite-derived agricultural data. J. Hydrometeorol. 2010, 11, 171.

46. Mesinger, F.; DiMego, G.; Kalnay, E.; Mitchell, K.; Shafran, P.C.; Ebisuzaki, W.; Jovic, D.; Woollen, J.; Rogers, E.; Berbery, E.H.; et al. North American regional reanalysis. Bull. Am. Meteorol. Soc. 2006, 87, 343-360.

47. Higgins, R.W.; Janowiak, J.E.; Yao, Y.P. A gridded hourly precipitation data base for the United States (1963-1993); US Department of Commerce, National Oceanic and Atmospheric Administration, National Weather Service:Silver Spring, MD, USA, 1996.

48. Kanamaru, H.; Kanamitsu, M. Model diagnosis of nighttime minimum temperature warming during summer due to irrigation in the California Central Valley. J. Hydrometeorol. 2008, 9, 1061-1072. 
49. Deardorff, J.W. Three-dimensional numerical study of the height and mean structure of a heated planetary boundary layer. Boundary-Lay. Meteorol. 1974, 7, 81-106.

50. Lackmann, G. Midlatitude Synoptic Meteorology: Dynamics, Analysis, and Forecasting; American Meteorological Society: New York, NY, USA, 2011.

51. Holton, J.R.; Hakim, G.J. An Introduction to Dynamic Meteorology; Academic press: Waltham, MA, USA, 2012.

52. Avissar, R.; Liu, Y. Three-dimensional numerical study of shallow convective clouds and precipitation induced by land surface forcing. J. Geophys. Res.: Atmos. (1984-2012) 1996, 101, 7499-7518.

53. Kustu, M.D.; Fan, Y.; Rodell, M. Possible link between irrigation in the US High Plains and increased summer streamflow in the Midwest. Water Resour. Res. 2011, doi:10.1029/2010WR010046.

54. Suyker, A.E.; Verma, S.B. Evapotranspiration of irrigated and rainfed maize-Soybean cropping systems. Agric. For. Meteorol. 2009, 149, 443-452.

55. Mahmood, R.; Foster, S.A.; Keeling, T.; Hubbard, K.G.; Carlson, C.; Leeper, R. Impacts of irrigation on 20th century temperature in the northern Great Plains. Glob. Planet. Chang. 2006, 54, 1-18.

56. Puma, M.; Cook, B. Effects of irrigation on global climate during the 20th century. J. Geophys. Res. Atmos. (1984-2012) 2010, doi:10.1029/2010JD014122.

57. Parry, M.L. Climate Change 2007: Impacts, Adaptation and Vulnerability: Working Group II Contribution to the Fourth Assessment Report of the IPCC Intergovernmental Panel on Climate Change; Cambridge University Press: Cambridge, UK, 2007; Volume 4.

58. Rogers, D.H.; Alam, M.; Shaw, L.K. Kansas Irrigation Trends; Agricultural Experiment Station and Cooperative Extension Service, Kansas State University: Manhattan, KS, USA, 2008.

59. Kenny, J.F.; Barber, N.L.; Hutson, S.S.; Linsey, K.S.; Lovelace, J.K.; Maupin, M.A. Estimated Use of Water in the United States in 2005; US Geological Survey: Reston, VA,USA, 2009.

60. Schaible, G.D.; Aillery, M.P. Water Conservation in Irrigated Agriculture: Trends and Challenges in the Face of Emerging Demands; US Department of Agriculture, Economic Research Service: Washington, DC, USA, 2012.

61. Steward, D.R.; Bruss, P.J.; Yang, X.; Staggenborg, S.A.; Welch, S.M.; Apley, M.D. Tapping unsustainable groundwater stores for agricultural production in the High Plains Aquifer of Kansas, projections to 2110. Proc. Natl. Acad. Sci. USA 2013, 110, E3477-E3486.

(c) 2014 by the authors; licensee MDPI, Basel, Switzerland. This article is an open access article distributed under the terms and conditions of the Creative Commons Attribution license (http://creativecommons.org/licenses/by/3.0/). 